\section{BIOTECNOLOGÍA: BIOSEGURIDAD Y BIOCUSTODIA EN LA INVESTIGACIÓN BIOTECNOLÓGICA}

\author{
Rafael Pérez Mellado \\ Centro Nacional de Biotecnología \\ Consejo Superior de Investigaciones Científicas \\ rpmellado@cnb.csic.es
}

Cómo citar este artículo/Citation: Pérez Mellado, R. (2014). "Biotecnología: bioseguridad y biocustodia en la investigación biotecnológica". Arbor, 190 (768): a150. doi: http://dx.doi. org/10.3989/arbor.2014.768n4004

Recibido: 9 junio 2014. Aceptado: 14 julio 2014.

RESUMEN: Los avances en Biotecnología y en Bioinformática han sido tan espectaculares en los últimos años que han llevado a la reconstrucción de agentes biológicos y al diseño y síntesis de cromosomas artificiales. Paradójicamente han sido estos avances los que han dificultado la puesta en práctica de mecanismos que permitiesen el control a nivel nacional e internacional sobre la transferencia de agentes biológicos naturales, genéticamente modificados o sintéticamente reconstruidos, limitando las capacidades nacionales para hacer frente a los compromisos contraídos en Tratados o Resoluciones Internacionales que prohíben el desarrollo, producción almacenamiento de armas biológicas y toxínicas, elevando las armas biológicas a la categoría de armas de destrucción masiva. Los códigos de conducta parecen una medida sencilla, de escasa interferencia en el desarrollo de la investigación científica y que permite evidenciar la transparencia del trabajo científico.

PALABRAS CLAVE: Bioseguridad; biocustodia; códigos de conducta.

\section{BIOTECNOLOGY: BIOSAFETY AND BIOSECURITY IN BIOTECHNOLOGICAL RESEARCH}

Copyright: ( 2014 CSIC. Este es un artículo de acceso abierto distribuido bajo los términos de la licencia Creative Commons Attribution-Non Commercial (by-nc) Spain 3.0.

ABSTRACT: Advances in Biotechnology and Bioinformatics have made such spectacular strides in the last few years that they have led to the reconstruction of biological agents and the design and synthesis of artificial chromosomes. Paradoxically, it is precisely these advances that have hindered the implementation of the mechanisms that would enable control over the transfer of natural, genetically modified or synthetically reconstructed biological agents on a national and international scale, by limiting the national ability to comply with the commitments made in the Treaties or International Resolutions that prohibit the development, manufacture and storage of toxin and biological weapons, raising biological weapons to the category of weapons of mass destruction. The codes of conduct seem to be a blunt instrument with little impact on the development of scientific research and highlighting the transparency of a scientific work.

KEYWORDS: Biosafety; biosecurity; codes of conduct. 


\section{INTRODUCCIÓN}

El extraordinario avance de la Biotecnología durante los últimos veinticinco años del pasado siglo y los primeros catorce del siglo XXI junto con el desarrollo de Tecnologías de la Información en el comienzo de este siglo, casi impensables en nuestro pasado reciente, ha permitido considerables aplicaciones de estos hallazgos científicos en innumerables facetas del desarrollo vital de los seres humanos, mejorando la calidad de nuestras vidas, pero, al mismo tiempo, han permitido que la Biotecnología, entendida como ese conjunto de técnicas y avances científicos, sea también una tecnología deseable por individuos y organizaciones que procuran una utilización torticera y malintencionada de los avances científicos. Tanto es así, que los agentes patógenos y los organismos recombinantes que han adquirido capacidades patogénicas, tienen la consideración de arma de destrucción masiva (ADM), alineándose con las armas químicas, radiológicas y nucleares.

Por más que debiera repugnar a la conciencia de la humanidad la utilización de la enfermedad como arma de destrucción, no deja de sorprendernos la capacidad de la especie humana para utilizarla con ese fin en repetidas ocasiones recogidas por la historia de la humanidad. Basten algunos ejemplos: Ya en el año 190 a. C. Aníbal ordenó arrojar ollas de barro conteniendo serpientes, cuya mordedura era venenosa, contra barcos enemigos en la batalla del río Eurymedon.

En el siglo XIV fue práctica frecuente durante los asedios arrojar cuerpos en estado de putrefacción al enemigo; así, en 1340, durante la Guerra de los Cien Años, el duque de Normandía lanzó cadáveres de caballos contra el castillo de Thyne Levesque (hoy Thun l'Évêque, norte de Francia) que había sido tomado por los ingleses; y en 1346 los mongoles catapultaron contra los tártaros cadáveres de víctimas de la peste en Caffa (hoy, Feodosia, Ucrania). Es particularmente conocida la distribución en 1763 por los británicos de mantas contaminadas en Fort Pitt. Las mantas provenían de un hospital donde se trataban enfermos de viruela y se distribuyeron a las tribus indias americanas.

La utilización de agentes biológicos no es ajena a los tiempos modernos. En la Primera Guerra Mundial unidades del ejército alemán llevaron a cabo acciones por las que se infectaba a los animales de carga de los aliados con las bacterias causantes del muermo (Burkbolderia mallei) o del carbunco (Bacillus anthracis). La infección era procurada directamente por líquido conteniendo la bacteria o con terrones de azúcar que contenían capilares de vidrio con el agente patógeno en forma líquida. En 1916 el Estado Mayor alemán evaluó solicitudes para dispersar la bacteria causante de la peste (Yersinia pestis) sobre el Reino Unido o contaminar los ríos fronterizos de España con Portugal con el bacilo del cólera (Vibrio cholerae). Afortunadamente, las dos solicitudes fueron denegadas por el Estado Mayor alemán. El conocimiento del programa de armamento biológico alemán provocó que Francia empezase su propio programa en 1922, después de la Primera Gran Guerra. La Unión Soviética empezó su programa en 1925 e Italia en 1932.

Aunque se pensó que Alemania había usado armas biológicas en la Segunda Guerra Mundial, cuando esta terminó se pudo comprobar que el programa de armamento biológico alemán era exclusivamente defensivo y que la utilización ofensiva de armas biológicas había sido prohibido explícitamente por el Estado Mayor alemán. Los programas biológicos de Francia y de la Unión Soviética continuaron durante la guerra y el Reino Unido, Estados Unidos y Canadá pusieron en marcha un programa conjunto. Japón comenzó un programa biológico ofensivo en 1932, después de la invasión de Manchuria en el que utilizaban bombas de porcelana para liberar pulgas que transmitían la peste, que infectaban a ratas y estas a su vez al hombre, y bombas de acero para liberar esporas de Bacillus anthracis sobre las ciudades chinas. También utilizaron Bacillus anthracis, Vibrio cholerae y Salmonella enterica en acciones de sabotaje de alimentos y pozos de agua. Los programas biológicos de Reino Unido, Estados Unidos y Canadá continuaron después de la Segunda Guerra Mundial, potenciados por el conocimiento del programa japonés. Tras ocupar Manchuria en 1945, la Unión Soviética conoció de la existencia del programa japonés y activó el suyo propio.

La dimensión de posprogramas nacionales de armas biológicas propició la aparición de iniciativas internacionales destinadas a frenar esa expansión. El Protocolo de Ginebra se firmó el 17 de junio de 1925 y entró en vigor el 8 de febrero de 1928. El Protocolo prohíbe el uso en la guerra de gases asfixiantes y el uso de armas biológicas, pero el Protocolo de Ginebra no prohíbe su producción y almacenamiento. La entrada en vigor del Protocolo supuso el fin en esa fecha de muchos de los programas de armamento biológico anteriormente mencionados pero, lamentablemente, no de todos ellos.

El 10 de abril de 1972, la Convención sobre la prohibición del desarrollo, de la producción y del almacenamiento de armas bacteriológicas (biológicas) y 
toxínicas y sobre su destrucción (CABT) quedó abierta para la firma. Entró en vigor el 26 de marzo de 1975, después de que 22 gobiernos signatarios depositaran los instrumentos de ratificación. Hoy 170 países forman parte de la CABT.

Sin embargo, la entrada en vigor de la CABT en 1975 no supuso un freno a la proliferación de armas biológicas: La Unión Soviética decidió continuar y potenciar su programa de armamento biológico por sospechar que los Estados Unidos no habían desmantelado el suyo, incumpliendo flagrantemente la CABT. La Unión Soviética anunció el fin de su programa biológico en marzo de 1992. La magnitud real del programa biológico de Irak fue conocida en 2003 durante la invasión de Irak y resultó ser mucho menos importante de lo inicialmente supuesto.

La calificación de la utilización de patógenos como armas de destrucción masiva y la creciente preocupación sobre su posible utilización por grupos terroristas, ha hecho necesaria la resolución 1540 del Consejo de Seguridad de Naciones Unidas de 2004 que insta a todos los Estados para que tomen medidas para prevenir el uso de armas de destrucción masiva, incluyendo armas químicas y biológicas, y su uso con fines terroristas.

\section{LA CABT}

El objetivo fundamental de la CABT es lograr progresos efectivos para un desarme general y completo que incluya la prohibición del desarrollo, la producción y el almacenamiento de armas bacteriológicas (biológicas) y su eliminación, mediante la adopción de medidas eficaces que faciliten el desarme general y prohíban y prevengan el uso de armas biológicas.

Las obligaciones en que incurren los Estados Partes de la CABT están desglosadas a lo largo de los 15 Artículos de la Convención. En síntesis, los Estados Partes se comprometen a no desarrollar, producir, ni almacenar ni traspasar a otros agentes y toxinas de naturaleza biológica sus equipos y medios de diseminación (vectores), así como a no utilizar armas biológicas o tóxinicas en conflicto armado. Los Estados Partes también se comprometen a destruir o desviar hacia fines pacíficos todos los agentes, toxinas, armas, equipos y vectores en tipos y en cantidades que no estén justificados para fines profilácticos, de protección u otros fines pacíficos.

A efectos de la CABT, los agentes biológicos son cualquier tipo de agente de naturaleza biológica, microbiana o no, naturales o recombinantes, y los pro- ductos de naturaleza tóxica de ellos derivados (toxinas), que tengan acción lesiva, incapacitante o letal sobre los seres humanos, los animales o las plantas. La mayor proporción de agentes biológicos son bacterias o virus (organismos procarióticos). Existen patógenos que son de naturaleza eucariótica pero microbianos, como algunos hongos y algunos parásitos. Algunos organismos causantes de plagas son de mayor tamaño (por ejemplo, moscas, mosquitos o escarabajos) y se consideran también agentes biológicos o vectores de agentes biológicos cuando contribuyen a la diseminación de los mismos (por ejemplo animales que propagan parásitos tengan los parásitos o no un ciclo vital en ellos). Todos los agentes biológicos son relevantes para la Convención. Los mismos patógenos que causan de forma natural enfermedades en el hombre, los animales o las plantas podrían ser utilizados en un conflicto armado. Su relevancia relativa vendrá definida por su forma de actuación o por su particular grado de virulencia.

Los agentes biológicos tienen características que los hacen particularmente apropiados como posibles armas de destrucción masiva y, en algunos casos, de difícil control.

- Son numerosos.

- Están ampliamente presentes en la naturaleza.

- Algunos de ellos son fácilmente accesibles.

- Su detección es con frecuencia difícil o requiere mucho tiempo.

- El manejo de algunos de ellos puede no requerir una gran especialización.

- Tienen un amplio espectro de blancos (humanos, animales, plantas).

- Pueden tener efectos devastadores en salud humana o animal o en agricultura.

- Sus efectos directos pueden causar grandes pérdidas económicas, deteriorando el bienestar social.

Un potencial ataque causando un brote biológico de consecuencias impredecibles califica a las armas biológicas como una preocupación real en materia de defensa y seguridad nacional.

\section{LA RESOLUCIÓN 1540 DE 2004 DEL CONSEJO DE SEGURIDAD DE LAS NACIONES UNIDAS}

Hay ejemplos relativamente recientes de la utilización de agentes biológicos en atentados terroristas: La secta japonesa Aum Shinrikyo (responsable del 
ataque con gas sarín en el metro de Tokio) diseminó una suspensión líquida de Bacillus anthracis desde un edificio en Kameido (Tokio), de una cepa que afortunadamente resultó no ser patógena, habiendo intentado también sin éxito el uso de la toxina botulínica. Hay pruebas de que Al Qaeda ha intentado desarrollar programas biológicos, desde el principio de los años noventa, aunque de escasa magnitud, que aparentemente terminó en 2003 , después de la invasión de Afganistán en 2001, aunque su interés en las armas biológicas parece que sigue vigente. La secta Rajneeshee contaminó en noviembre de 1984 restaurantes de la ciudad The Dalles, Oregon en 1984 en Estados Unidos para influir en el resultado de las elecciones locales, dando lugar a varios brotes de salmonelosis con 751 personas intoxicadas. El 18 de septiembre de 2001, después del atentado contra las Torres Gemelas en Nueva York (USA) se enviaron por correo regular los primeros sobres conteniendo $\mathrm{Ba}$ cillus anthracis (conocido como Amerithrax) y el 5 de octubre del mismo año fallecía la primera persona por inhalación de la bacteria. En total se produjeron veintidós casos de carbunco en Estados Unidos, once por inhalación y once cutáneos, cinco de los afectados por inhalación fallecieron.

Así pues, las particulares características de los agentes biológicos enumeradas más arriba, no solo los hacen candidatos a posibles agentes para su utilización en conflictos armados, como armas de destrucción masiva, sino también a su posible utilización por organizaciones terroristas, de nuevo calificando a los agentes biológicos como materia de preocupación para la seguridad nacional. Por ello, el Consejo de Seguridad de Naciones Unidas en su Resolución 1540, tipifica las armas biológicas como armas de destrucción masiva y "Decide que todos los Estados se abstengan de suministrar cualquier tipo de apoyo a los agentes no estatales que traten de desarrollar, adquirir, fabricar, poseer, transportar, transferir o emplear biológicas y sus sistemas vectores". "Decide también que todos los Estados, de conformidad con sus procedimientos nacionales, adopten y apliquen leyes eficaces apropiadas que prohíban a todos los agentes no estatales la fabricación, la adquisición, la posesión, el desarrollo, el transporte, la transferencia o el empleo de armas biológicas y sus sistemas vectores, en particular con fines de terrorismo, así como las tentativas de realizar cualquiera de las actividades antes mencionadas, participar en ellas en calidad de cómplices, prestarles asistencia o financiarlas". "Decide también que todos los Estados adopten y hagan cumplir medidas eficaces para instaurar controles nacionales a fin de prevenir la proliferación de biológicas y sus sistemas vectores", y para ello:

a) Establezcan y mantengan medidas eficaces y apropiadas para rendir cuenta de esos artículos en su producción, uso, almacenamiento o transporte y mantenerlos en condiciones de seguridad;

b) Establezcan y mantengan medidas eficaces apropiadas de protección física;

c) Establezcan y mantengan controles fronterizos eficaces apropiados y medidas para hacer cumplir la ley con el fin de detectar, desalentar, prevenir y combatir, incluso por medio de la cooperación internacional cuando sea necesario, el tráfico y la intermediación en el comercio ilícitos de esos artículos, de conformidad con sus atribuciones legales y su legislación nacional y con arreglo al derecho internacional;

d) Establezcan, desarrollen, examinen y mantengan controles nacionales eficaces y apropiados de la exportación y reexpedición de esos artículos, con inclusión de leyes y reglamentos adecuados para controlar la exportación, el tránsito, la reexpedición y la reexportación, y controles del suministro de fondos y servicios relacionados con esas exportaciones y reexpediciones, como la financiación y el transporte que pudieran contribuir a la proliferación, así como controles de los usuarios finales y establezcan y apliquen sanciones penales o civiles adecuadas a las infracciones de esas leyes y reglamentos de control de las exportaciones.

\section{BIOSEGURIDAD Y BIOCUSTODIA}

Tanto por lo que se refiere a la CABT como a la Resolución 1540, los Estados quedan obligados a tutelar y regular el uso y el acceso a los agentes biológicos. Por complejo que pueda parecer el lenguaje de tipo legal que acompaña a las resoluciones y tratados internacionales, en esencia, en el caso de los agentes biológicos, en gran medida todo se circunscribe a la comprensión y correcta aplicación nacional de dos conceptos básicos: Bioseguridad y Biocustodia.

¿Qué se entiende por Bioseguridad?: La noción común de biosafety (en español bioseguridad) se deriva de las directrices impartidas por la Organización Mundial de la Salud (OMS) sobre las técnicas que se utilizan en los laboratorios. Según el Manual de Bioseguridad en el Laboratorio (OMS, 2003), bioseguridad o seguridad biológica es el término utilizado para referirse a: "Los principios, técnicas y prácticas aplica- 
das con el fin de evitar la exposición no intencional a patógenos y toxinas, o su liberación accidental". EI concepto es coherente con los equivalentes de FAO (Organización de Naciones Unidas para la Agricultura y la Alimentación) y OEI (Organización Mundial de Sanidad Animal).

La CABT recoge la siguiente definición para el término Bioseguridad: "Los principios, tecnologías, procedimientos y medidas puestas en práctica para prevenir la liberación accidental o la exposición intencionada a agentes biológicos y toxinas y para proteger a la población y al medio ambiente de los efectos de tal liberación", que es muy similar al de la OMS.

En realidad se podría utilizar una definición simplificada e igualmente coherente de Bioseguridad: "La protección de las personas, animales o plantas contra los patógenos".

Según la CABT las medidas de Bioseguridad se refieren y deben afectar a instalaciones (animalarios, invernaderos, piscicultura, fermentación, etc.) y laboratorios tanto del sector público como privado y al transporte y movilidad de patógenos y toxinas en lo que refiere a la protección de personas, animales, plantas y el medio ambiente contra esos patógenos y toxinas. La implantación a nivel nacional de esas medidas requiere de la existencia de la correspondiente legislación. En España y en los países de la UE existe normativa que permite razonablemente el cumplimiento de las obligaciones contraídas en relación con la CABT.

¿Qué se entiende por Biocustodia? La noción de biosecurity (en español biocustodia) no se puede derivar de las definiciones de la OMS. La traducción de biosecurity por bioprotección aparece en el Manual de Bioseguridad en el Laboratorio de la OMS en su traducción al español publicada en 2005, donde biosecurity es el término utilizado para referirse a: "La protección del material microbiológico contra el robo, la pérdida o la desviación para evitar que esos agentes se puedan utilizar de forma indebida para atentar contra la salud pública". Que la propia OMS redefinió después en la World Health Organization Biorisk Management: Laboratory Biosecurity Guidance de septiembre de 2006 (WHO, 2006): La biosecurity en el laboratorio describe la protección, control y responsabilidad asociada a materiales biológicos valiosos dentro de los laboratorios, para prevenir el acceso no autorizado, pérdida, robo, mala utilización, desviación o liberación intencional". Estas definiciones introducen a su vez conceptos nuevos, que pre- cisarían de adecuadas definiciones por sus implicaciones legales, como "material microbiológico" que excluya a lo que no sea microbiológico en primer lugar y descalifica a los seres vivos, ya que estos pudieran no ser considerados "materiales" desde el punto de vista legal. La posterior precisión donde los materiales han pasado a ser "biológicos" sobrepasando la calidad microbiológica sin dejar de ser "materiales" para adquirir la calidad de "valiosos" tampoco ayuda demasiado, pues introduce otra presunta imprecisión legal adicional al tener que definir qué es "valioso" y qué no lo es dentro de un laboratorio. Por otro lado la propia OMS reconoce que el término biosecurity es complejo, ya que ha evolucionado simultáneamente en varios procesos y se utiliza de forma diferente en cada uno de ellos. De hecho el término biosecurity no parece tener un significado uniforme en los sectores de la salud humana, animal y vegetal. En veterinaria y en agricultura (FAO) el término ha pasado a significar la protección de los recursos biológicos contra especies foráneas o invasoras.

Biosecurity es un término confuso y con significado diferente en distintos sectores. Por ello España, de acuerdo con las Delegaciones de habla hispana en la CABT, propuso en agosto de 2008 (Biological Weapons Convention, 2008) el término Biocustodia como traducción de Biosecurity para designar el conjunto de medidas pertinentes en el seno de la CABT.

\section{BIOCUSTODIA: ALCANCE, REQUERIMIENTOS Y MEJORA DE LA APLICACIÓN A NIVEL NACIONAL}

La CABT entiende que las medidas de Biocustodia deben tener un alcance que se concreta en:

- Abarcar los agentes, las toxinas y el equipo crítico.

- Abarcar las instalaciones, el almacenamiento, el transporte y el personal.

- Ser eficaces en relación con el costo.

- Basarse en criterios de gestión del riesgo.

- Basarse en claras directrices nacionales.

- Estar destinadas a lugares específicos, dado que los cambios de circunstancias excluyen una reglamentación común universal.

- Hacer uso de mecanismos de supervisión y normas.

- Adaptar cuando sea posible los marcos de supervisión o reglamentación existentes.

- Someterse regularmente a revisión. 
Asimismo, la CABT considera que las medidas de Biocustodia requieren de:

- Buenas prácticas científicas.

- Listas flexibles de control nacional.

- Exigencias de empaquetado y etiquetado.

- Sistemas de supervisión y control del acceso en las instituciones pertinentes.

- Control de los antecedentes del personal.

- Actividades de vigilancia integral e integrada.

- Identificación e inventario de las instalaciones, los sistemas de transporte y el personal pertinentes.

- Un mecanismo para crear y mantener inventarios detallados y exactos de la posesión, el transporte, el almacenamiento y el empleo de los recursos pertinentes y el personal autorizado para trabajar con ellos.

En estricto cumplimiento de la Resolución 1540 y de las directrices dimanadas de la CABT y de la importancia atribuida a nivel nacional, el Consejo de Ministros aprobó en su reunión del 30 de junio de 2013 la Estrategia de Seguridad Nacional que incluye específicamente la adopción de un Plan Nacional de Biocustodia entre sus objetivos, recogiendo así las recomendaciones del Consejo de Seguridad de NN.UU. y de la CABT, que indican la conveniencia de:

- Elaborar un plan nacional de Biocustodia.

- Identificar un organismo principal del gobierno o crear una nueva autoridad supervisora central.

- Incorporar las medidas de Biocustodia en la regulación de prácticas óptimas y otras directrices sin fuerza legal.

Es lógico pensar que el Plan Nacional de Biocustodia debería incluir estas dos últimas recomendaciones así como revisar e implementar si fuera necesario el alcance y requerimientos mencionados más arriba.

\section{CÓDIGOS DE CONDUCTA}

Un Código de conducta es un conjunto de normas vinculantes para un colectivo profesional, que marca la deontología de la actuación profesional de ese colectivo. Por su naturaleza, un código de conducta podría ser una medida de Biocustodia regulatoria de buenas prácticas profesionales y podría ser un elemento de mejora en la aplicación nacional de la CABT y de la Resolución 1540.
Los códigos de conducta están siendo objeto de discusión en la CABT desde el año 2005, y son muchos los países que ven en ellos un elemento importante de refuerzo a nivel nacional de la CABT, hasta el punto de que algunos de estos países ya los han adoptado y otros muchos están considerando su adopción. Estos códigos de conducta deberían ser de aplicación para las profesiones involucradas en materia de Biocustodia en sentido amplio, tanto para profesionales del sector público como del privado y de aplicación tanto en las instalaciones de investigación del sector público como del sector privado.

De las posibles características que estos códigos de conducta puedan tener, hay dos que han sido reconocidas como de mayor importancia relativa: 1 ) los códigos no deben entrar en contradicción o enfrentamiento con otros códigos ya existentes y 2 ) los códigos deben ser flexibles, al objeto de que puedan evolucionar de acuerdo con la evolución de los avances científicos y tecnológicos. Veamos un ejemplo ilustrativo de cada caso: 1) La obediencia debida: El Dr. Ken Alibek, Vicedirector del programa de armas biológicas de la antigua Unión Soviética, desertó a Estados Unidos en 1992. Ken Alibek, que también era militar, esgrimió la obediencia debida a sus superiores para justificar su falta al "Juramento del Médico" al dirigir un programa de armas de destrucción masiva. 2) El propio "Juramento del Médico", también conocido como "la declaración de Ginebra" que se basa en el "Juramento Hipocrático", fue adoptado por la 2. a Asamblea General de la Asociación Médica Mundial en Ginebra, Suiza, en septiembre de 1948 donde, entre otras cosas, el médico "promete solemnemente mantener sumo respeto por la vida humana desde el momento mismo de la concepción". La declaración de Ginebra de 1948 ha sufrido diversas actualizaciones a lo largo de estos años. Desde 2006, esa "promesa solemne" ha pasado a ser "velar con el máximo respeto por la vida huma$n a^{\prime \prime}$, adaptándose así a las diferentes legislaciones actuales que reconocen el derecho al aborto. Es decir, un código de conducta debería evitar que el profesional tuviese que decidir su conducta como sujeto de actividades cuyos fines pueden ser opuestos, como en primer caso, y al mismo tiempo debería tener la flexibilidad del segundo caso para guiar la conducta del profesional dentro de la legalidad vigente.

En este sentido, España ha propuesto junto con otros países (Chile, Colombia, España, Italia y México) en la reunión de la CABT de diciembre de 2012 un código de conducta para científicos (Biological Weapons Convention, 2012) de posible aplicación general para 
todo el personal que utilice en su trabajo métodos científicos, tanto en ciencias naturales como sociales, médicas, veterinarias, agrícolas, matemáticas e ingenierías y que sean relevantes para la Convención sobre Armas Biológicas. El Código propuesto reconoce su utilidad para los científicos y personal técnico de las especialidades mencionadas, pero también alinea en la responsabilidad a las instituciones, tanto públicas como privadas, donde esos científicos y técnicos prestan sus servicios, por entender que las instituciones también deben velar por el cumplimiento del conjunto de normas vinculantes que determinan deontología de su actuación profesional.

\section{AVANCES CIENTÍFICOS Y TECNOLÓGICOS: TRANSFE- RENCIA DE ELEMENTOS TANGIBLES E INTANGIBLES}

Los avances científicos y tecnológicos y su posible incidencia en la aplicación a nivel nacional de han estado siempre presentes en las deliberaciones de la CABT. La propia naturaleza dual de los agentes biológicos: tanto pueden ser empleados para fines pacíficos o profilácticos, como pueden ser utilizados con fines hostiles. En vista del extraordinario desarrollo de la Ingeniería Genética durante la década de los ochenta, la CABT organizó un Grupo de trabajo (VEREX, 1992-1993) donde expertos de los Estados Partes de la Convención decidieron si, a pesar de ese desarrollo, se podría redactar un mecanismo de verificación del cumplimiento del articulado de la Convención. El trabajo de los expertos concluyó que, en aquel momento, el diseño de un protocolo de verificación era posible y con ese fin se constituyó un Grupo ad hoc de expertos con el mandato de afrontar ese desafío. Los trabajos del Grupo ad hoc se extendieron desde 1994 hasta 2001. En ese momento es cuando se adquiere el convencimiento de que la ciencia evoluciona a una velocidad que la diplomacia no puede seguir: durante ese periodo se publica la secuenciación del genoma de la levadura, del primer genoma bacteriano y de otros genomas, entre ellos el humano, haciendo prácticamente imposible diseñar un sistema de verificación que pueda tener en cuenta desarrollos tecnológicos y científicos cuya previsión temporal y su proyección posterior en el tiempo parecían impredecibles.

Los últimos avances logrados en secuenciación de genomas gracias a la Pirosecuenciación ("Next Generation Sequencing, NGS") que permite obtener hasta un millón de secuencias entre 60 y 400 nt de longitud han sido relativamente tan rápidos que han ido por delante de la tecnología informática necesaria para ensamblar las secuencias generadas, lo que parece que se empieza a resolver con la utilización de nue- vos supercomputadores aparentemente capaces de analizar simultáneamente el equivalente de hasta 240 genomas humanos en 50 horas.

Con todo lo fascinante que esto pueda parecer, lo es aún más la aparición de lo que se conoce como Biología sintética que permite la ingeniería de organismos capaces de realizar funciones que les eran ajenas y la reconstrucción de genomas y microorganismos vivos. Así el virus de la influenza que causó la pandemia de 1918-1919 (lo que se llamó y aún se llama "la gripe española") donde fallecieron 50 millones de personas en todo el mundo. El virus reconstruido (Tumpey et al., 2005) causó la muerte de ratones y de embriones de pollo, siendo capaz de replicarse en alta concentración en células epiteliales de bronquios humanos. La publicación de los trabajos de transmisión del virus zoonótico de la gripe aviar H5N1 no ha estado exenta de polémica hasta que su publicación fue finalmente autorizada (Imai et al., 2012; Herfst et al., 2012). La reciente publicación de la síntesis del cromosoma 3 de levadura, "synIII" (Annaluro et al., 2014), no hace sino significar una vez más magnitud en la progresión del avance científico.

La razón última por la que la reconstrucción de especies virales o la de la síntesis de cromosomas de diseño resultan de especial preocupación y relevancia en materias relacionadas con la CABT o con la Resolución 1540 es la dificultad inherente para monitorizar la presunta transferencia de tecnología y de agentes biológicos, sean genéticamente modificados o no. En ambos casos se insta a los Estados a que controlen la fabricación, el transporte la transferencia o el empleo de armas biológicas y sus vectores, y a que pongan en práctica medidas eficaces para instaurar controles nacionales. Se entiende, pues, que los desarrollos científicos mencionados no hagan sino aumentar las dificultades para ejercer ese control, y, en definitiva, para ejercer una Biocustodia eficaz.

La Biocustodia comprende medidas encaminadas a custodiar elementos relacionados con tecnología relevante, incluyendo elementos tangibles e intangibles. Son elementos tangibles "obvios" los patógenos, las vacunas, los equipos científicos e industriales etc., y el material de doble uso en general, pero también, aunque quizá "menos obvios", lo son planos, diagramas, modelos, fórmulas, diseños de ingeniería, especificaciones en manuales, procedimientos, libros, revistas especializadas, informes técnicos, etc. Por tanto, debería existir legislación que regule la transferencia y el transporte de elementos tangibles "obvios" y "menos obvios". 
Son elementos intangibles la asistencia técnica, el entrenamiento, los servicios de consultoría, las presentaciones científicas y comerciales, así como datos técnicos presentes en elementos tangibles que se puedan transmitir por medios "intangibles", como el correo electrónico, Internet, fax, discos compactos (CD), discos versátiles digitales (DVD), lápices de memoria, etc. Por lo tanto, debería existir legislación que regule la transferencia y el transporte de elementos intangibles.

Siendo no tarea fácil controlar la transferencia de elementos tangibles obvios y menos obvios, resulta labor de extraordinaria dificultad controlar la transferencia de elementos intangibles. Por ello son pocas todas las medidas que se puedan adoptar para facilitar esa tarea sin interferir con el normal y necesario desarrollo de la investigación y el avance tecnológico. La adopción de códigos de conducta del tipo descrito más arriba es un paso en ese sentido de aplicación relativamente sencilla, con un grado de interferencia muy pequeño en la investigación científica y que permite evidenciar la transparencia que los científicos tenemos en el normal desarrollo de nuestra profesión.

\section{BIBLIOGRAFÍA}

Annaluro, N. (2014). Total synthesis of a functional designer eukaryotic chromosome. Science, 344, pp. 55-58. http:// dx.doi.org/10.1126/science.1249252

Biological Weapons Convention (2008). Examen de las medidas nacionales, regionales e internacionales para mejorar la bioseguridad y la bioprotección, en particular la seguridad en el laboratorio y la seguridad de patógenos y toxinas [en línea]. Disponible en:http://www. opbw.org/new_process/mx2008/BWC_ MSP_2008_MX_INF.1_Sp.pdf

Biological Weapons Convention (2012). “Codigo de conducta para científicos". BWC/ MSP/2012/WP.9. Disponible en http:// www.unog.ch/_80256ee600585943.ns f/\%28httpPages\%29/89835cb0a2daa4a
0c1257b6e003415c5?OpenDocument\& ExpandSection=1\#_Section1

Herfst, S., Schrauwen, E. J. A., Linster, M., Chutinimikul, S., Wit, E. de, Munster, V. J., Sorrell, E. M., Bestebroer, T. M., Burke, D. F., Smith, D. J., Rimmelzwaan, G. F., Osterhaus, A. D. M. E. y Fouchier, R. A. M. (2012). Airborne transmission of influenza A/H5N1 virus between ferrets. Science, 336, pp. 1534-1541. http:// dx.doi.org/10.1126/science.1213362

Imai, M., Watanabe, T., Hatta, M., Das, S. C., Ozawa, M., Shinya, K., Zhongi, G., Hanson, A., Katsura, H., Watanabe, S., Li, C., Kawakami, E., Yamada, S., Kiso, M,, Suzuki, Y., Maher, E., Neumann, G. y Kawaoka, Y. (2012). Experimental adaptation of an influenza H5 HA con- fers respiratory droplet transmission to a reassortant H5 HA/H1N1 Virus in ferrets. Nature, 486, pp. 420-428.

Organización Mundial de la Salud (2005). Manual de Bioseguridad en el Laboratorio (3.a edición). Ginebra: Organización Mundial de la Salud.

Tumpey, T. M., Basler, C. F., Aguilar, P. V., Zeng, H., Solórzano, A., Swayne, D. E., Cox, N. J., Katz, J. M., Taubenberger, J. K., Palese, P. y García-Sastre, A. (2005). Characterization of the reconstructed 1918 Spanish influenza pandemic virus. Science, 310, pp. 77-80. http://dx.doi. org/10.1126/science.1119392

World Health Organization (2006). Biorisk management: Laboratory biosecurity guidance. World Health Organization. 